\title{
FLUXO DE TRABALHO LASERSCAN-BIM APLICADO À CONSERVAÇÃO E REABILITAÇÃO DO PATRIMÓNIO
}

\author{
André Azevedo $^{(1)}$, Joel Ribeiro ${ }^{(2)}$, Tiago Campelo ${ }^{(3)}$ \\ (1) Buildgest Lda, Porto \\ (2) Buildgest Lda, Porto \\ (3) Buildgest Lda, Porto
}

\begin{abstract}
Resumo
A preservação do edificado implica um conhecimento profundo da pré-existência para que seja possível a sua integração na reabilitação. As atividades ligadas à inspeção, tais como, análise documental, caracterização estrutural e construtiva, e o reconhecimento das principais anomalias podem considerar-se como tarefas imprescindíveis em medidas de preservação do património. A inclusão de toda a informação num modelo 3D, aplicando a metodologia BIM introduz vantagens face à transmissão desta pelo método tradicional na medida em que a consulta da informação por parte dos intervenientes é facilitada, e o modelo torna-se um elemento dinâmico e evolutivo com condições para agregar dados de futuras intervenções. A Buildgest tem vindo a implementar de forma progressiva a metodologia BIM nos processos de inspeção ao edificado existente, muitas vezes antecedido de recolha e tratamento de informação do edificado com recurso a tecnologia de digitalização (laserscan) aumentando o grau de fiabilidade do levantamento existente e, consequentemente, acrescentar aos stakeholders um maior nível de conhecimento para as intervenções de reabilitação a realizar. Este fluxo de trabalho é transmitido num modelo, que centraliza toda a informação, e é conduzido aos intervenientes, dotado de ferramentas que permite a integração com os modelos das diferentes especialidades, a consulta de informação do elemento estrutural pretendido, ensaios realizados, anomalias, fotos, etc. Estes tipos de metodologias de carácter inovador revelam-se interessantes no potencial crescente como repositórios de informação do património, contemplando aspetos que transcendem a mera informação gráfica ou descritiva, muitas vezes escassa ou deslocalizada, aumentando a qualidade na informação transmitida, proporcionando um arquivo inteligente e evolutivo das intervenções efetuadas ao longo da existência do património (Heritage BIM).
\end{abstract}

\section{Introdução}

O presente artigo reflete os trabalhos desenvolvidos pela Buildgest aplicados na área da reabilitação, durante a fase de inspeção e diagnóstico, com a metodologia laserscanning to BIM. 
Building Information Model (BIM) tem sido uma metodologia em constante desenvolvimento na área Arquitetura, Engenharia e Construção (AEC) na última década e a aposta de eleição dos várias empresas do setor em Portugal. Apesar da digitalização dos processos no desenvolvimento de construções novas, verifica-se um desenvolvimento moroso na adaptação das mesmas metodologias e ferramentas às atividades de reabilitação e gestão do património existente. São inúmeras as potencialidades da empregabilidade das novas tecnologias ao interesse da preservação do parque edificado, como a digitalização do existente através da nuvem de pontos, documentação de informação centralizada através da metodologia BIM e gestão do património com metodologia Facility Management (FM).

Neste artigo, apresenta-se a metodologia e ferramentas de trabalho da Buildgest, explorada e aperfeiçoada ao longo dos últimos 3 anos e aplicada na área da Inspeção e Diagnóstico dos edifícios. A metodologia consiste, a par dos métodos tradicionais de inspeção e diagnóstico das pré-existências e deteção de causas de anomalias, na digitalização do edificado através de laserscan, processamento e posteriormente a interpretação dos dados, documentação da informação e transmissão da mesma num modelo centralizado BIM, ver Figura 1. Nos capítulos seguintes do artigo são apresentados os processos de laserscan-BIM e posteriormente os diversos casos práticos com aplicação de diferentes métodos de documentação digital que incorporam ativos quantitativos (objetos inteligentes, dados de anomalias) e ativos qualitativos (fotografias, documentos de arquivo, relatórios de ensaios e de Inspeção e diagnóstico (I\&D)). Os casos práticos variam em escala e complexidade.

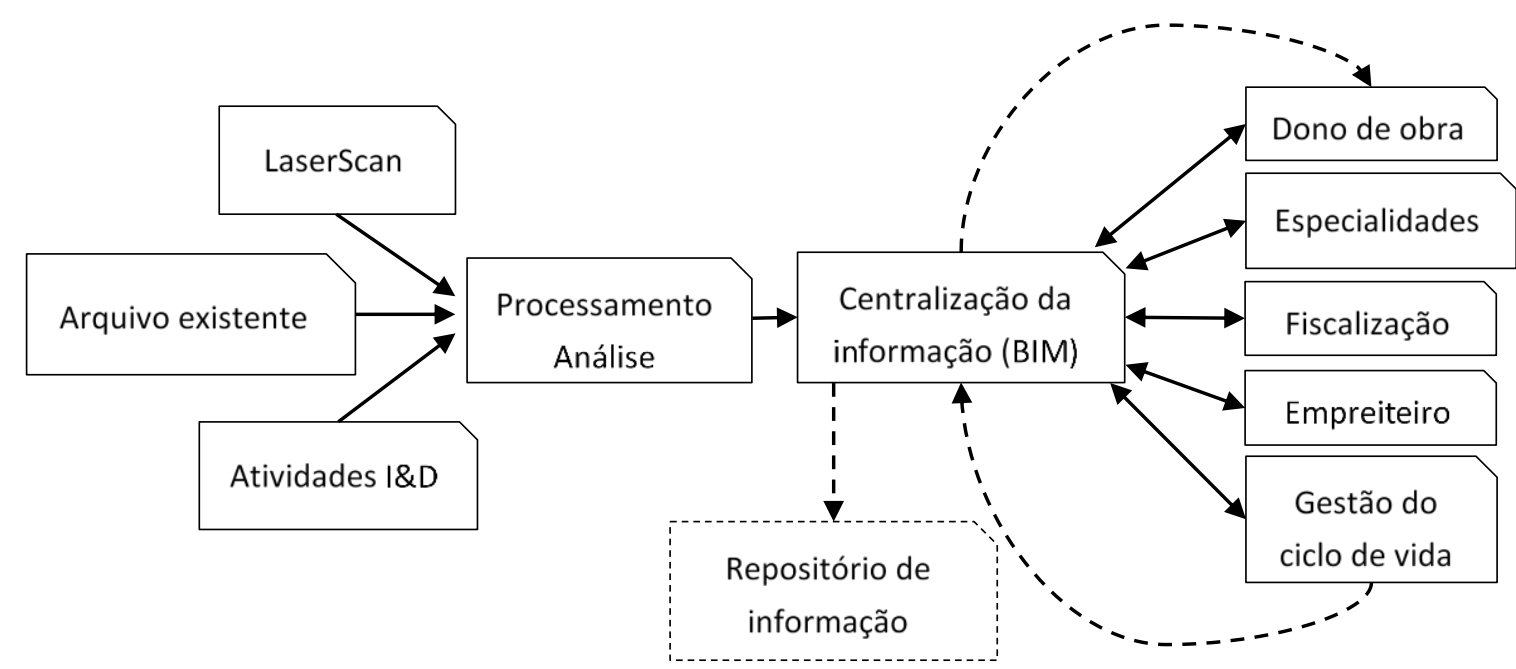

Figura 1: Workflow da metodologia de trabalho Laserscan-BIM aplicada à I\&D e documentação da informação.

\section{Laserscan e processamento de dados}

Esta tecnologia é baseada na reflexão de milhares de pontos para cada estação em que o equipamento é colocado, realizando uma conexão entre as várias estações que permitem a montagem de uma nuvem de pontos global, em que cada ponto tem uma cor associada e encontra-se localizado num sistema de eixos tridimensionais, permitindo medir distâncias entre eles e caracterizar qualquer objeto visível. A nuvem de pontos pode ser usada como base para 
transformar dados num modelo BIM criando um conjunto de bases de trabalho do modelo tridimensional da arquitetura existente e de um futuro projeto.

Os mais recentes equipamentos de laserscan e os sistemas de fotogrametria revelam-se atualmente uma ferramenta na recolha precisa do património construtivo existente. A recolha em locais culturalmente importantes, como edifícios históricos e monumentos, pode servir para uma variedade de aplicações. A informação recolhida pode auxiliar na conservação, reparação e gestão de ativos além de possivelmente servir como um recurso visual para fins educacionais e culturais. É elevado o potencial e capacidade técnica destes sistemas inovadores como um meio para a documentação do património, luxuosamente detalhado, com elevada precisão. Os dados adquiridos atuam como uma ferramenta de preservação digital e uma representação virtual intemporal do património como ele existe.

Além de um instrumento de digitalização das construções, surge também como ferramenta fundamental nas campanhas de I\&D da Buildgest para caracterização patológica, nomeadamente, o registo e quantificação de deformações no plano e fora do plano, de pavimentos, paredes de alvenaria, encurvadura de elementos estruturais verticais, entre outros. Utilizando leituras intervaladas é possível identificar os incrementos de deformação das superfícies, utilizando assim o laserscan como uma ferramenta de monitorização.

A metodologia da digitalização das construções utilizada pela Buildgest enquadra-se na realização de uma campanha abrangente ao património edificado, fornecendo um registo 3D objetivo do mesmo, capturando a sua condição atual, incluindo qualquer dano pré-existente nos elementos, assentamentos do edifício e alterações estruturais, permitindo no final a sua célere quantificação. A informação capturada fornece um conjunto de dados para a monitorização, conservação do edificado e enquadramento de alterações futuras.

\subsection{Sistemas de registo}

Nos casos de estudo desenvolvidos e apresentados no presente artigo em capítulo próprio, toda a informação tridimensional recolhida do património existente foi efetuada com recurso aos equipamentos BLK 360 e ScanStation P40 da Leica Geosystems. Ambos os equipamentos são ideais para projetos de registo tridimensional interior e exterior, devido à sua velocidade, alcance, resolução de dados, peso e o sistema de câmeras integradas High Definition Range (HDR). Os equipamentos utilizam um laser, que é invisível e classificado como inofensivo, completamente seguro para o operador e público sendo esta uma preocupação quando se efetuam trabalhos de registo em exteriores com elevada movimentação. A emissão de feixes laser e a leitura da sua distância de reflexão é executada com uma taxa de aquisição de dados excecionalmente alta e rápida principalmente comparada com o método tradicional, com a leitura de cerca de 360 mil pontos por segundo, mantendo um erro de $6 \mathrm{~mm}$ a $10 \mathrm{~m}$ de distância. Os equipamentos têm um alcance aproximado de cerca de $60 \mathrm{~m}$ e geram dados de uma leitura $360^{\circ}$.

\subsection{Metodologia de registo Laserscan}

$\mathrm{Na}$ generalidade, um dos principais objetivos do registo tridimensional com laserscan é a captura explicita das continuidades arquitetónicas e a sucessão dos elementos estruturais. $\mathrm{O}$ posicionamento do equipamento durante as campanhas é estrategicamente definido em função da melhor vista panorâmica para o scanner e posteriormente posições que cubram os pontos cegos. Posteriormente são definidos pontos de controlo, para um correto controlo sobre o resultado final. Os pontos de controlo são georreferenciados com recurso a uma estação total 
que referencia alvos/pontos que fazem parte integrante da informação digitalizada do edifício (nuvem de pontos), ver Figura 2 e Figura 3.

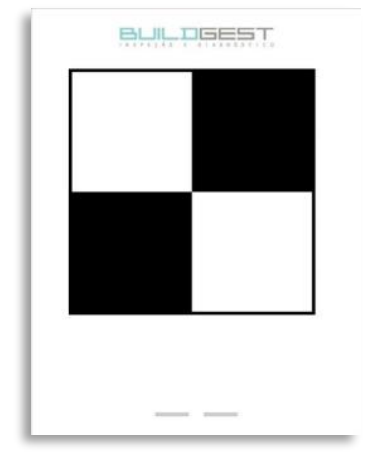

Figura 2: Alvo tipo.

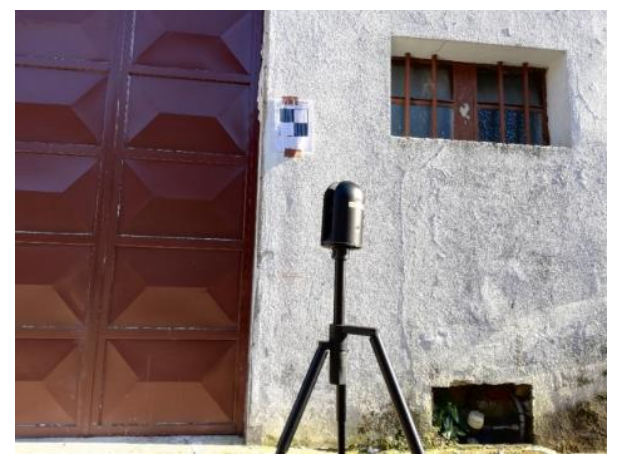

Figura 3: Utilização de alvos durante a campanha de digitalização.

O primeiro passo de processamento da informação associada à digitalização do património consiste na organização da inúmera informação recolhida. Posteriormente, são executados os registos dos scans usando o software Leica Cyclone, ou semelhante, usando o alinhamento automático e manual. Naturalmente, orientando uma campanha de digitalização programada e bem definida, viabilizando uma elevada percentagem de overlap entre scans durante o registo e a utilização de pontos de controlo georreferenciados diminui consideravelmente a ausência de informação na nuvem de pontos global.

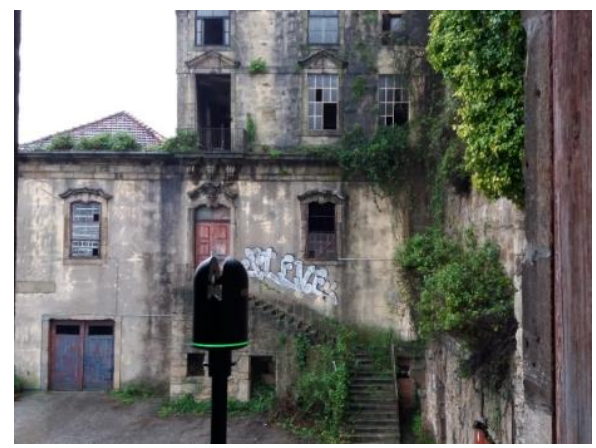

Figura 4: Digitalização de uma fachada - Porto.

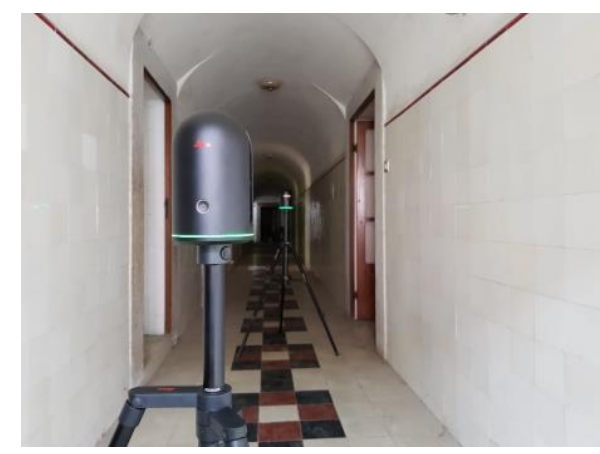

Figura 5: Captura da geometria de uma abóbada com recurso a Laserscan.

\section{BIM e documentação do património}

A adoção da metodologia BIM no setor de novas construções tem sido conduzida pelos resultados positivos demonstrados na eficiência, redução de custos e aumento de produtividade em fases operacionais.

Os mesmos benefícios podem ser perspetivados na utilização desta ferramenta na gestão do património existente com vantagens adicionais em termos de coordenação espacial das intervenções (com a introdução de nuvem de pontos e Clash Detection), planeamento das medidas de reabilitação, conservação e manutenção (através da melhoria substancial da 
informação centralizada). Este reconhecimento do BIM deve-se por ser uma metodologia evolutiva que abraça a crescente demanda por uma base de conhecimento multidisciplinar, essencial para a gestão de processos de ciclo de vida e o desenvolvimento do inventário patrimonial e cultural existente.

No workflow definido pela Buildgest, a representação dos trabalhos executados no património existente, é realizada através de componentes digitais que, ao contrário das ferramentas clássicas, não pretende representar apenas a sua localização e aparência, mas também as suas propriedades geométricas, resultados de ensaios não destrutivos (NDT), elementos de arquivo histórico associado, etc. Este método permite a criação de um repositório central para toda a informação histórica existente, geométrica e não geométrica, dados operacionais, campanhas de arqueologia, caracterização e análise de materiais, entre outras. O laserscan de sondagens arqueológicas e posterior introdução da mesma num modelo BIM é um exemplo prático de informação centralizada do achado com informação tridimensional e localização exata.

É essencial nas intervenções realizadas no património a perceção da condição histórica, informações de arquivo e o conhecimento profundo do edificado antes da sua intervenção. Pretende-se com esta metodologia que o modelo BIM centre nele toda a informação relevante e exequível para que sirva de base de informação detalhada a todos os intervenientes durante a reabilitação do edifício. O modelo BIM é assim um processo de apoio à colaboração multidisciplinar, para uma melhor gestão da informação aplicado ao património existente (Heritage BIM).

A digitalização do património existente e a sua documentação num modelo centralizado é um procedimento complexo que normalmente envolve abordagens híbridas para a visualização de conjuntos de informação heterogénea, tais como, memórias descritivas, elementos gerados por malhas, geometrias, registo fotográfico, etc. Contudo, apesar da complexidade revela-se uma metodologia que acrescenta valor às entidades envolvidas nos processos, quer pela facilidade de consulta e acesso ao acervo de informação gerada quer pela própria desmaterialização dos elementos físicos normalmente associados (desenhos, relatórios etc...).

\section{Casos de estudo}

Os exemplos apresentados no presente capítulo resultam de um conjunto de trabalhos desenvolvidos pela Buildgest nos últimos anos aplicando a metodologia acima descrita. Este conjunto consiste numa série de exemplos distintos que evidenciam os benefícios da metodologia para a obtenção e transmissão de informação.

$\mathrm{Na}$ tabela seguinte apresenta-se um quadro resumo dos casos de estudo abaixo apresentados:

Tabela 1: Exemplo para o PTBIM

\begin{tabular}{lccc}
\hline Caso de Estudo & Localização & Data & Área de construção \\
\hline Caso A & Porto & 2017 & $30000 \mathrm{~m}^{2}$ \\
Caso B & Vila Nova de Gaia & 2018 & $20240 \mathrm{~m}^{2}$ \\
Caso C & Porto & 2017 & $20081 \mathrm{~m}^{2}$ \\
Caso D & Braga & 2019 & Objeto isolado \\
\hline
\end{tabular}




\section{CASO A - PORTO 2017}

Um emblemático edifício da cidade do Porto em que a sua construção é datada dos finais da década de 40 e início da década de 50 apresenta uma área de implantação de cerca de $2600 \mathrm{~m}^{2}$. Tendo em conta a dimensão do edifício e devido à falta de coerência entre os limites representados nos elementos de arquivo e os limites construídos, assim como a escassez de elementos 2D com representação de cortes no interior do edifício foram contratualizados serviços de levantamento laserscan, modelação As Built (Figura 6) e inspeção e diagnóstico da estrutura existente.
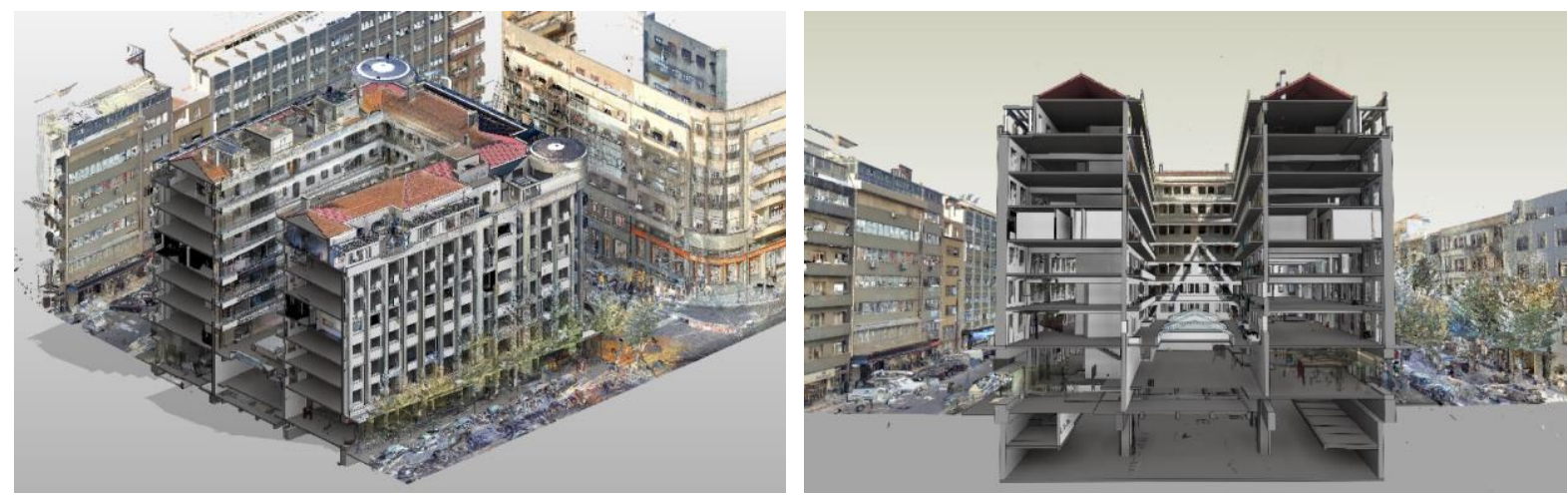

Figura 6: Integração da pointcloud e modelo As Built do edifício.

O modelo centraliza toda a informação e foi transmitido a todos os intervenientes dotado de objetos que permitem conhecer as armaduras, resultados de ensaios de caracterização dos materiais, estado de conservação e/ou fotos de anomalias visíveis. Na Figura 7 apresenta-se um exemplo da aplicação e leitura do objeto inserido sobre um elemento estrutural com resultado da leitura com deteção de armadura.

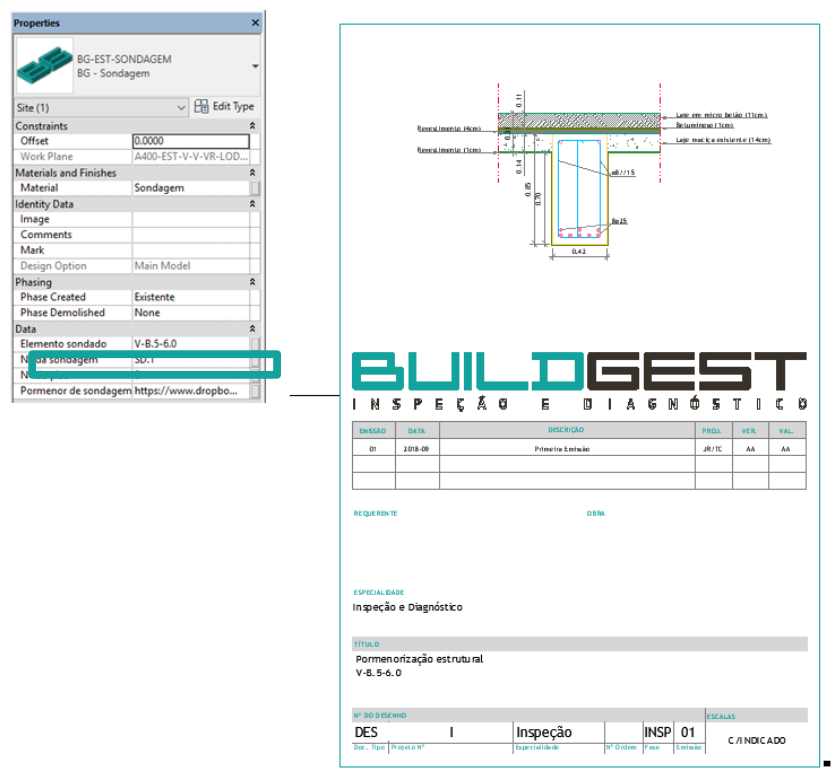

Figura 7: Consulta da informação centralizada no modelo. 


\section{CASO B - VILA NOVA DE GAIA 2018}

Outro exemplo de objeto com informação foi aplicado no levantamento e construção do modelo tridimensional de armazéns vinícolas em Vila Nova de Gaia, Porto. O objeto é apresentado com destaque e compreende o relatório de inspeção e diagnóstico individual de cada nave, Figura 8.

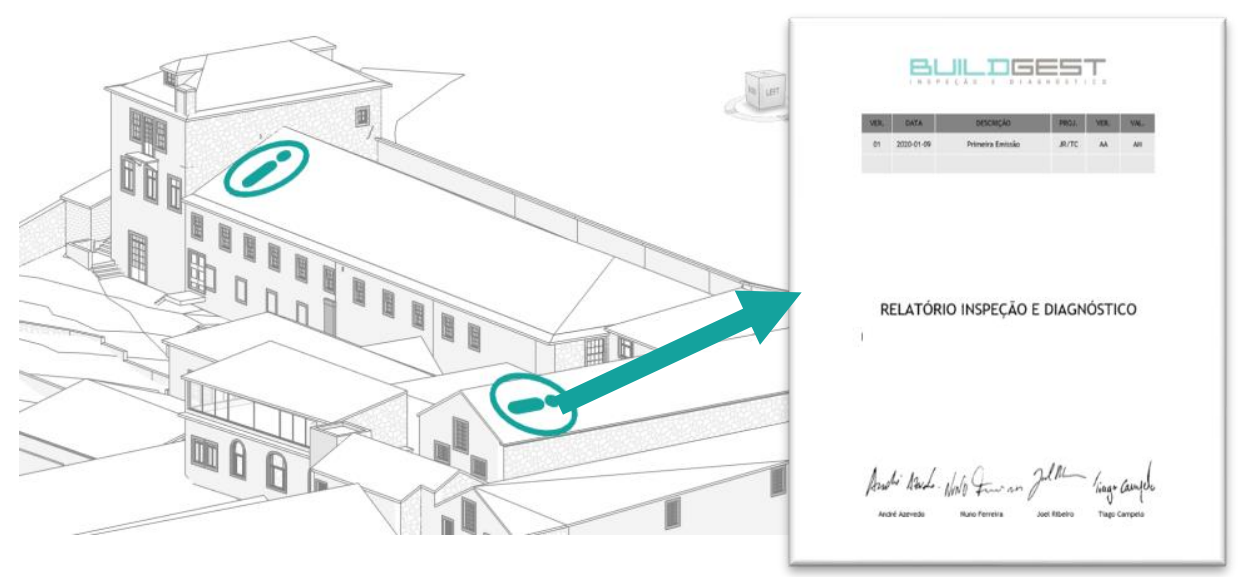

Figura 817: Objeto com relatório de inspeção e diagnóstico associado.

A informação recolhida através do laserscan não serviu unicamente como uma base para a construção de um modelo tridimensional do existente mas também como ferramenta de quantificação das deformações fora-do-plano das paredes de alvenaria e deformação vertical e encurvadura lateral das asnas existentes. Na Figura 9 representa-se um corte efetuado na nuvem de pontos que permite observar e quantificar a deformação fora-do-plano do topo da alvenaria (cerca de $37 \mathrm{~cm}$ ).

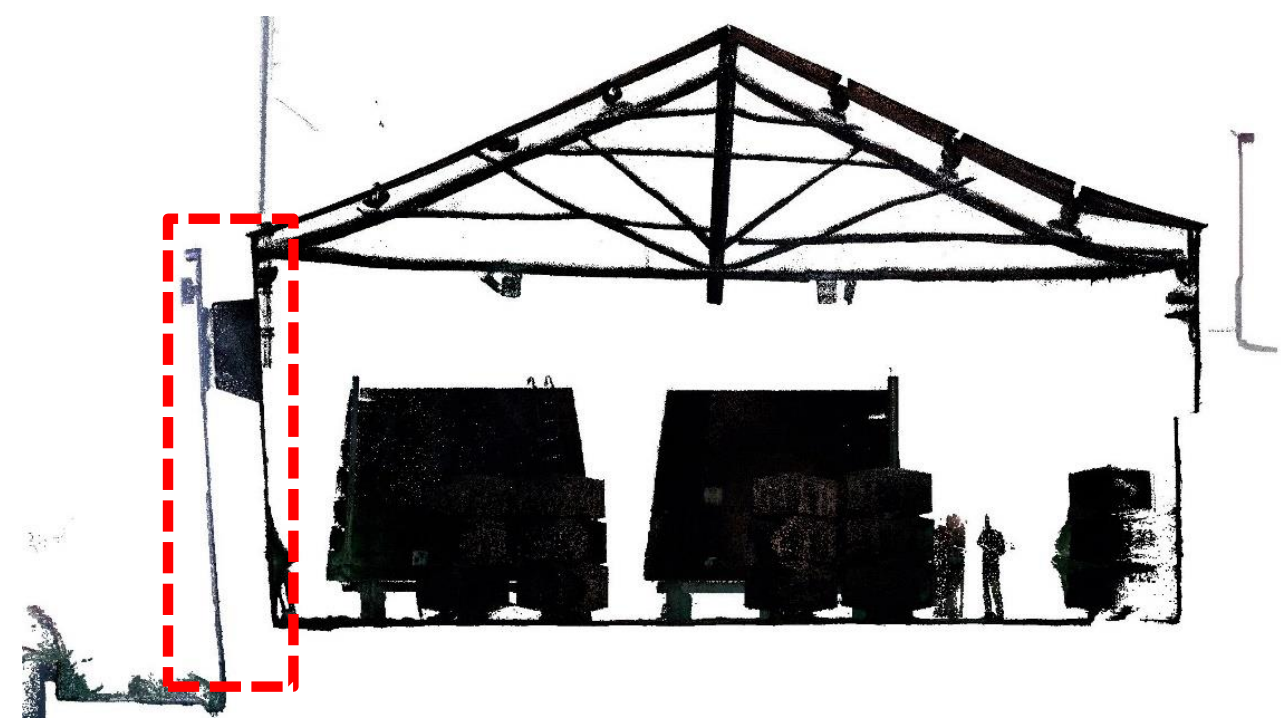

Figura 9: Deformação de uma parede de alvenaria com deslocamento de $37 \mathrm{~cm}$ no topo.

Ainda decorrente das campanhas de inspeção e diagnóstico desenvolvidas no armazém vinícola, das conclusões formalizadas com base na inspeção visual e ensaios de caracterização 
efetuados aos elementos de madeira das asnas da cobertura, foi disponibilizada uma ferramenta intuitiva de visualização gráfica dos elementos de madeira em mau estado de conservação. $\mathrm{O}$ objeto representativo do elemento de madeira (asna) contém informação acerca do seu estado de conservação assim como fotografias recolhidas na campanha de inspeção ou resultados dos ensaios, Figura 10.

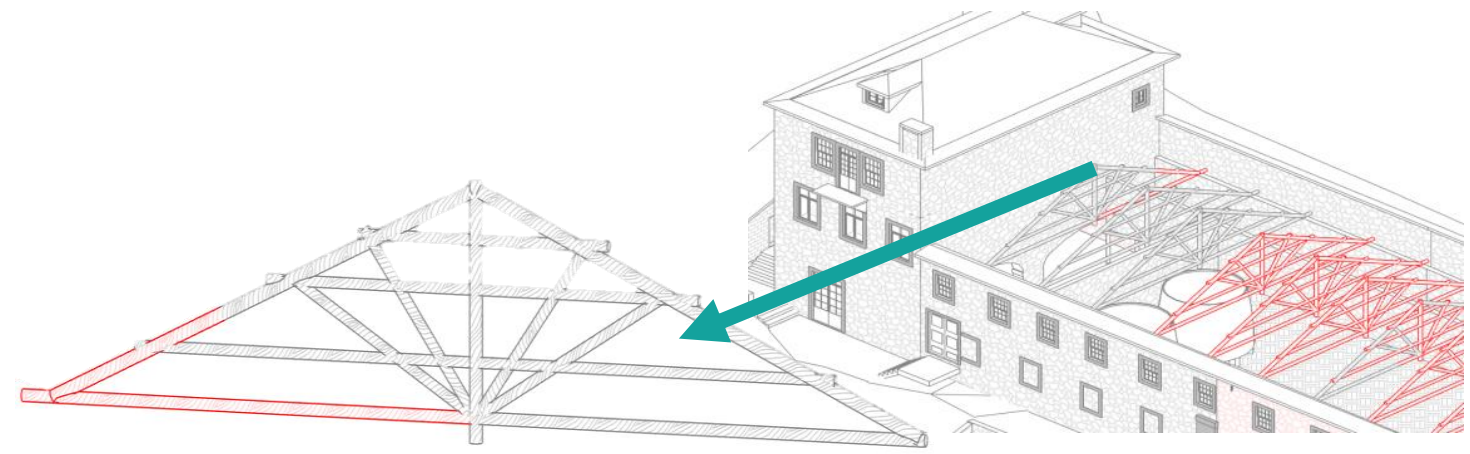

Figura 10: Representação gráfica dos elementos de madeira das asnas em mau estado de conservação.

\section{CASO C - PORTO 2017}

Outro trabalho desenvolvido como exemplo da aplicação da mesma abordagem são os trabalhos desenvolvidos no antigo Pavilhão Rosa Mota em que o levantamento tridimensional da préexistência e o mapeamento das anomalias foram integrados num mesmo modelo. $\mathrm{O}$ mapeamento foi realizado com recurso à implantação de objetos em que cada um representava uma anomalia e contem informação relativa à gravidade, extensão da anomalia e um registo fotográfico associado a cada uma anomalia, ver Figura 11.

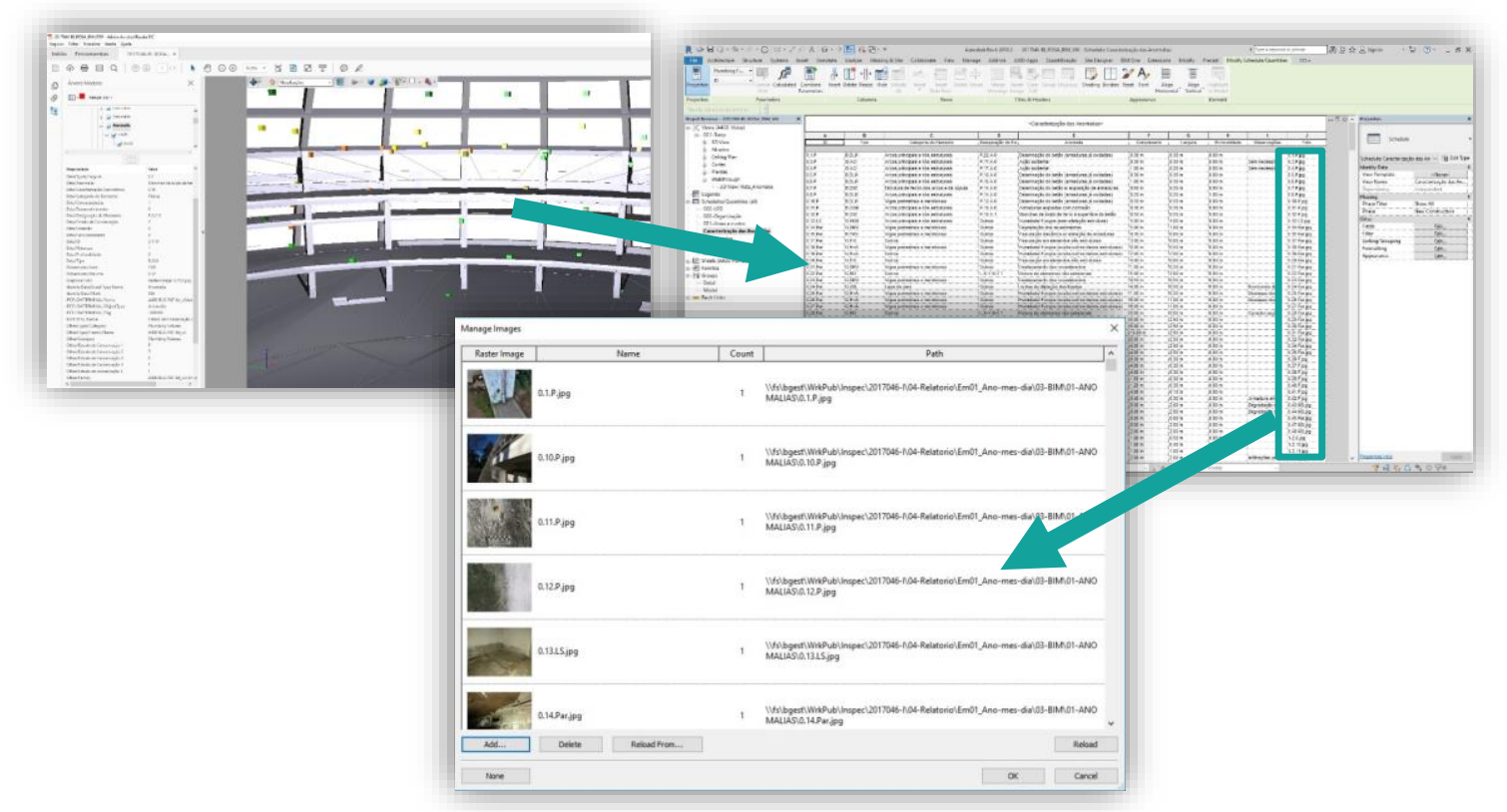

Figura 11: Registo de anomalias no Pavilhão Rosa Mota. 
A informação dos trabalhos realizados no Pavilhão Rosa Mota partiu de uma base preparada pela Buildgest a partir da informação recolhida pelo laserscan. Essa base consistiu num modelo do edifício existente que foi evoluído e enriquecido com informação desde a fase de inspeção e diagnóstico até a fase do projeto de execução sendo um forte contributo para o aumento de produtividade em fase de projeto e redução de custos na fase de execução, ver Figura 12.

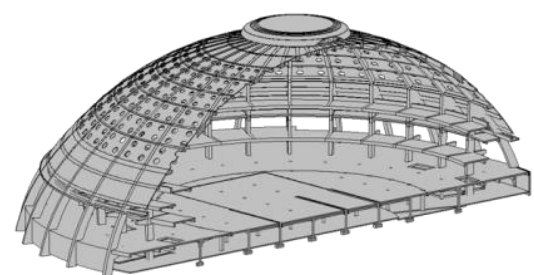

Edifício Existente

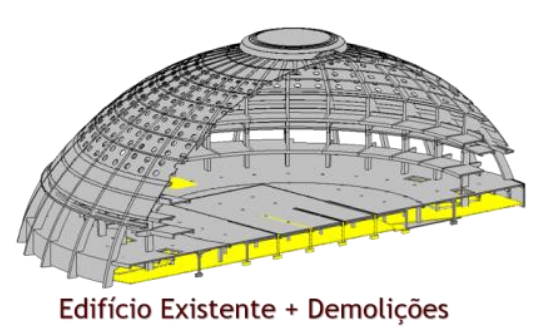

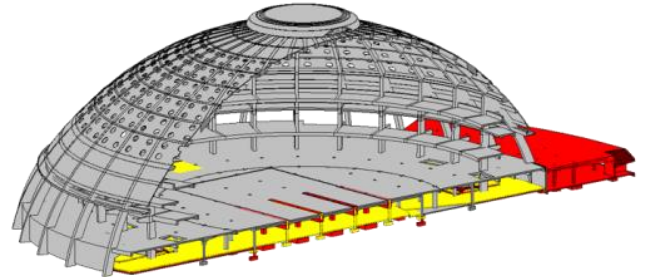

Edifício Existente + Demolições + Novas Construções

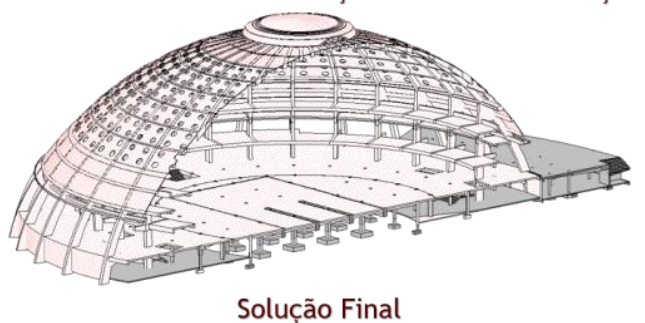

Figura 12: Modelo BIM do antigo Pavilhão Rosa Mota.

\section{CASO D - BRAGA 2019}

O último caso de estudo consiste na representação fiel de uma escultura de uma fonte existente no logradouro de um antigo convento. O estudo consistiu na digitalização do objeto, determinação do seu estado de conservação e posterior representação num software de modelação BIM. O processo consistiu no registo digital com laserscan com posterior transformação da nuvem de pontos numa malha densa de planos e a integração desses elementos num modelo Revit. Apesar do resultado final em termos de representação ter-se revelado bastante satisfatório, percebeu-se que a atribuição de informação ao objeto é muito limitada e como tal reduz a capacidade de utilização do mesmo como objeto BIM. No entanto, reconhecese que são inúmeras as aplicações desta metodologia na reabilitação destes elementos como por exemplo a reprodução de moldes ou outras cópias iguais aos elementos pré-existentes, ver Figura 13. 


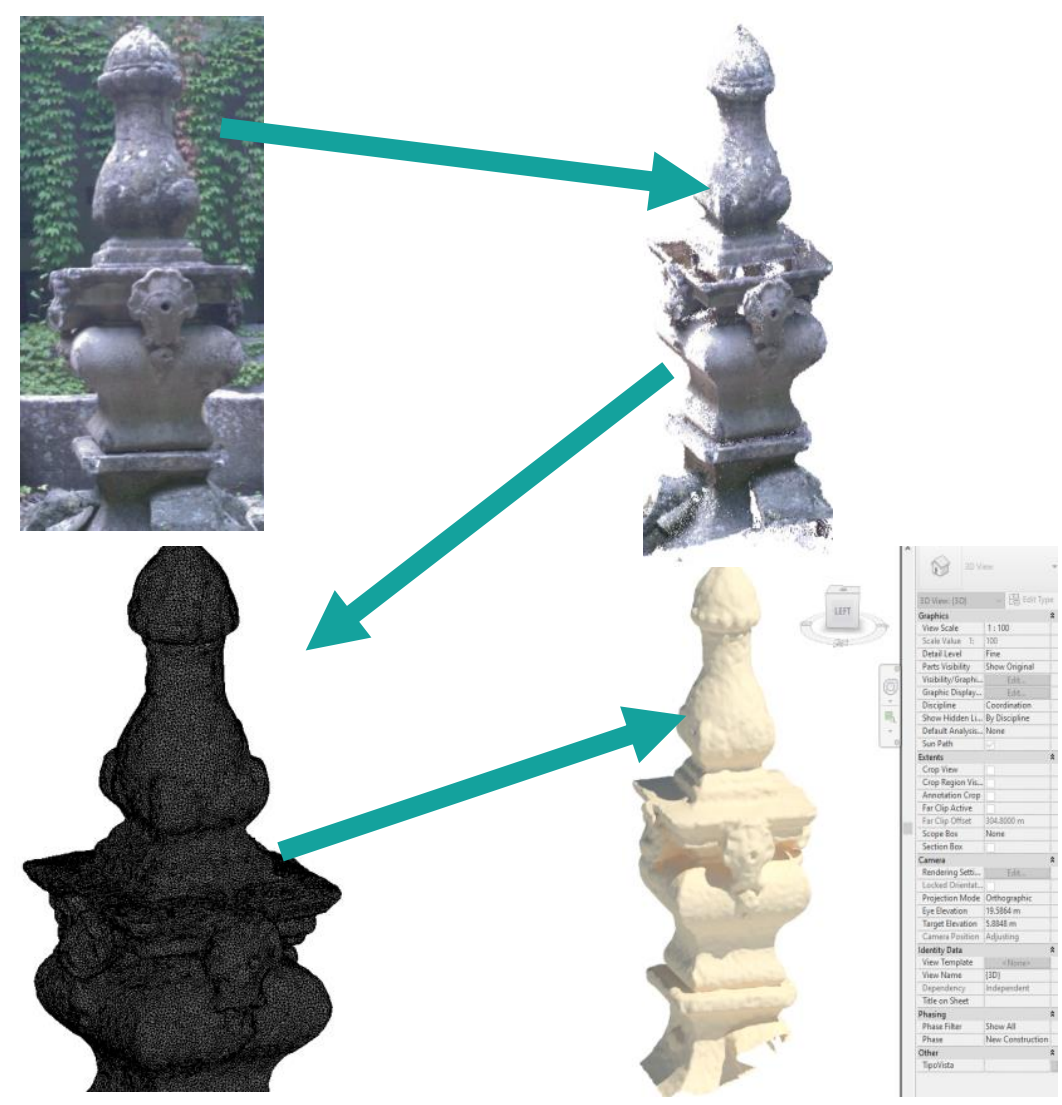

Figura 13: Utilização de laserscan, malhas e modelo Revit para representação do objeto.

\section{Conclusão}

Este artigo destaca a aplicação intensiva das ferramentas laserscan e BIM na aquisição, digitalização, centralização e partilha da informação. A utilização de scans de diversas posições de curto alcance e diferentes níveis altimétricos prova ser uma maneira eficaz de documentar digitalmente estruturas patrimoniais de diferentes escalas e complexidades. A longo prazo o conjunto de dados constituirá uma base para o desenvolvimento de medidas de intervenção informada e sustentável. Estes dados podem servir igualmente para ilustrar a ciclo de vida de um edifício. O desenvolvimento da tecnologia laserscan poderá no futuro servir inclusive de estudos da deterioração da superfície de esculturas ou como base para reprodução e restituição da escultura original.

A heterogeneidade da informação é um grande obstáculo na reabilitação do património. Durante um projeto, os dados são armazenados em diferentes locais e em formatos de software específicos. O objetivo da metodologia aplicada é fornecer à indústria da reabilitação do patrimônio um fluxo de trabalho que permita uma documentação mais abrangente e a criação de modelos geométricos mais realistas com informação mais centralizada. As informações nas fases consecutivas do processo devem ser acessíveis pelas diferentes partes envolvidas. Isso permite que os usuários reutilizem o modelo, permitindo a distribuição de informações ao longo do projeto e a redução de tempo de tomada de decisão uma vez que a informação se encontra, na generalidade, disponível num só local. 
Para futuro desenvolvimento desta metodologia aplicada à reabilitação do património existente, propõe-se uma base de dados BIM partilhada com objetos parametrizados representativos da generalidade dos pormenores arquitetónicos e com informação associada sobre os métodos de construção específicos para a sua conservação/ reabilitação.

\section{Referências}

[1] Adami, A., Fregonese, L., Rosignoli, O., Scala, B., Taffurelli, L., and Treccani, D.: Geometric Survey Data And Historical Sources Interpretation For Hbim Process: The Case Of Mantua Cathedral Façade, Int. Arch. Photogramm. Remote Sens. Spatial Inf. Sci., XLII2/W11, 29-35, https://doi.org/10.5194/isprs-archives-XLII-2-W11-29-2019, 2019.

[2] David M. Barber, Ross W. A. Dallas \& Jon P. Mills (2006) Laser Scanning for Architectural Conservation, Journal of Architectural Conservation, 12:1, 35-52, DOI: 10.1080/13556207.2006.10784959

[3] GOMES, Joana Isabel Neves (2018). Nova sala de espetáculos: Teatro Ana Pereira Alenquer. Do laser Scan à modelação BIM: experiências e testemunhos. Lisboa: ISCTEIUL, 2018. Dissertação de mestrado.

[4] Barber, D. M., Dallas, R. W., \& Mills, J. P. (2006). Laser scanning for architectural conservation. Journal of Architectural Conservation, 12:1, 35-52. 